\title{
Prototipagem rápida e fabricação digital em ateliê vertical: do processo à materialização
}

\author{
Rapid prototyping and digital fabrication in vertical atelier: from process to materialization \\ - Paula Batistello \\ Universidade Comunitária da Região de \\ Chapecó, Brasil \\ paula@batistello.com.br \\ - Katiane Laura Balzan \\ Universidade Comunitária da Região de \\ Chapecó, Brasil \\ katilaura@unochapeco.edu.br \\ Luana Peroza Piaia \\ Universidade Comunitária da Região de \\ Chapecó, Brasil \\ luanapiaia@unochapeco.edu.br \\ - Juliano Miotto \\ Universidade Comunitária da Região de \\ Chapecó, Brasil \\ jmiotto@unochapeco.edu.br
}

\begin{abstract}
The evolution of techniques and digital tools has aided and complemented actions in the design process, generating alternatives and reducing costs in short times. This paper reports experience that integrated the rapid prototyping in vertical atelier, in one of Pronto $3 D$ network institution member. The results shows that use of rapid prototyping technology contributes to design improvement process applied to teaching of architecture and urbanism, mainly in relation of identification in failures and conflicts of proposals, which eventually pass unnoticed by students in different phases of the course.
\end{abstract}

Keywords: Rapid Prototyping in Architecture and Urbanism, Architectural Design Process, Vertical Atelier in Architecture and Urbanism

\section{Introdução}

A evolução de novas técnicas e ferramentas computacionais para a elaboração e desenvolvimento de projetos arquitetônicos e a constante utilização dos mesmos, apresenta gradativamente resultados positivos no desenvolvimento dos projetos. A partir de projetos digitais comunicáveis com máquinas de fabricação digital, as tecnologias digitais auxiliam no processo de projeto através da fabricação de maquetes ou modelos em diferentes escalas, inclusive nas dimensões reais dos objetos. Para Florio e Tagliari (2011), representação física de um modelo digital é fundamental para a correta avaliação do projeto de arquitetura, pois permite materializá-la. É neste domínio que se encontram os protótipos rápidos, cumprindo o papel de traduzir arquivos digitais tridimensionais em modelos físicos. A materialização de projetos por meio de prototipagens rápidas torna a compreensão da proposta arquitetônica inteligível.

A Prototipagem Rápida é um instrumento que auxilia e complementa as ações no processo de projeto, de modo a criar e produzir, em um curto espaço de tempo, protótipos reais e concretos de seus projetos, gerando alternativas na hora da apresentação dos mesmos. Isso diferencia a imagem bidimensional e facilita a compreensão e a percepção dos envolvidos no processo. Para Oliveira e Fabricio (2009) o uso de novas ferramentas como scriptings, algoritmos e softwares paramétricos marcam uma mudança na prática da arquitetura e no método de ensino. Visando contribuir com a formação do profissional projetista, capaz de atender à demanda do mercado, a universidade precisa estar preparada para oferecer meios e ferramentas a fim de subsidiar a formação do aluno. É neste âmbito que surge a Rede Pronto 3D - Prototipagem Rápida e Novas Tecnologias Orientadas ao 3D. A rede está inserida em quatro escolas do Estado de Santa Catarina, onde são ofertados cursos de Arquitetura e Urbanismo e Design, e objetiva auxiliar as diferentes etapas do projeto através da pesquisa, criação, desenvolvimento e produção de modelos, maquetes e produtos. Desta maneira cada escola possui equipamentos automatizados para a fabricação de protótipos, variando entre impressoras $3 \mathrm{D}$, fresadoras e cortadoras a laser de modelos variados, para que haja troca de técnicas e produtos finais entre os participantes da rede.

Fabricio e Miyasaka (2015), definem fabricação digital como um processo desde a concepção até a construção em que é necessária a tradução de representação gráficas do projeto em dados que serão traduzidos por maquinários de produção. Reforçam que alguns aspectos da tradução estão relacionados com a conexão entre o arquiteto e a capacidade da máquina. Isto aumenta a necessidade de os arquitetos entenderem como essas ferramentas funcionam, que tipos de materiais são aplicáveis e também onde estão as oportunidades para novas possibilidades.

Neste campo, o presente artigo relata experiência aplicada em uma das instituições que compõem a rede. A 
experiência ocorreu em forma de ateliê vertical, como uma maratona de projetos, integrando acadêmicos do $1^{\circ}$ ao $11^{\circ}$ período do curso de Arquitetura e Urbanismo da instituição, e teve como objeto de projeto o desenvolvimento de um parklet para uma das principais avenidas da cidade. A fabricação digital e a prototipagem rápida foram inseridas no processo de projeto em dois momentos. O primeiro momento permitiu a materialização da proposta como modelo reduzido e compôs os elementos de entrega para avaliação dos projetos pela banca examinadora da maratona, o que permitiu a criação de um caminho para discussão e ponderação de diferentes alternativas e soluções para o equipamento em questão. 0 segundo momento constituiu a execução da proposta em escala 1:1 pela equipe vencedora, permitindo a instalação do parklet em tamanho real no município.

\section{Procedimentos Metodológicos}

A $3^{\text {a }}$ Maratona de Projetos - Ateliê Vertical, do Curso de Arquitetura e Urbanismo da Unochapecó, foi executada em quatro etapas, descritas a seguir:

i) Etapa de Conhecimento da Temática: Momento em que foi apresentado às equipes o regulamento da maratona e ministrada uma palestra sobre a temática de parklets, com o presidente do Instituto Mobilidade Verde, Lincoln Paiva, responsável pela elaboração e implantação de vários parklets em São Paulo, Belo Horizonte e Rio de Janeiro. O parklet, definido pelo artigo $2^{\circ}$ do decreto 55.045/2014 é "[...] uma ampliação do passeio público, realizada por meio da implantação de plataforma sobre a área antes ocupada pelo leito carroçável da via pública, equipada com bancos, floreiras, mesas e cadeiras, guarda-sóis, aparelhos de exercícios físicos, paraciclos ou outros elementos de mobiliário, com função de recreação ou de manifestações artísticas. " (São Paulo, 2014). Também nesta etapa foi feita a organização das equipes e reuniões técnicas explanando sobre o processo de fabricação digital e prototipagem rápida para que os projetos fossem executados dentro do sistema CAD (Compute Aided Design) CAM (Computer Aided Manufacturing). Um dos requisitos do edital foi a quantidade de chapas que seriam disponibilizados para a execução do produto final, na escala 1:1. É importante ressaltar que até este período não havia nenhuma disciplina específica de Prototipagem Rápida e Fabricação Digital em andamento no curso, sendo este um importante momento de contato dos acadêmicos com as novas tecnologias.

ii) Etapa de Projetação e Integração de Saberes entre Equipes: As equipes, que foram compostas por acadêmicos do $1^{\circ}$ ao $11^{\circ}$ períodos, tiveram cinco semanas para trocar saberes entre os membros, fazer levantamento da área e desenvolver a proposta. Amálgamas de diversos períodos são importantes para equilibrar os conhecimentos a serem aplicados, instigar a criatividade e observar expectativas de diferentes níveis de repertórios. As diretrizes mínimas que deveriam ser atendidas pela proposta foram: a) Uso exclusivamente público; b) Concepção modular para fácil remoção; c) Impacto da intervenção do fluxo de pessoas; d) Sustentabilidade; e) Requisitos técnicos de piso (segurança, acessibilidade, drenagem e estrutura); proteções laterais; mobiliário (acessibilidade, manutenibilidade e temporalidade); sinalização e comunicação visual. Nesta etapa as equipes utilizaram os ateliês de projeto para desenvolvimento das propostas e o laboratório Pronto 3D para fabricação das maquetes. Os projetos foram desenvolvidos em softwares de livre escolha por parte dos acadêmicos, sendo que os mais utilizados foram ArchiCad, SketchUp, Revit e AutoCad. É importante ressaltar que, como a fabricação digital é efetivada a partir de modelos tridimensionais, foi estimulado o uso de softwares BIM para esta atividade e salienta-se ainda que o curso em questão optou por ensinar aos acadêmicos a projetar apenas em softwares desta natureza, reforçando a utilização das novas tecnologias no processo de ensino de projeto arquitetônico e urbanístico. Depois de desenvolverem o modelo tridimensional virtual, os projetos foram planificados com apoio de softwares como Pepakura e 123DMake e então, as maquetes foram fabricadas em MDF $3 \mathrm{~mm}$, com corte a laser e sistema de encaixes e/ou colagens (Figura 1).

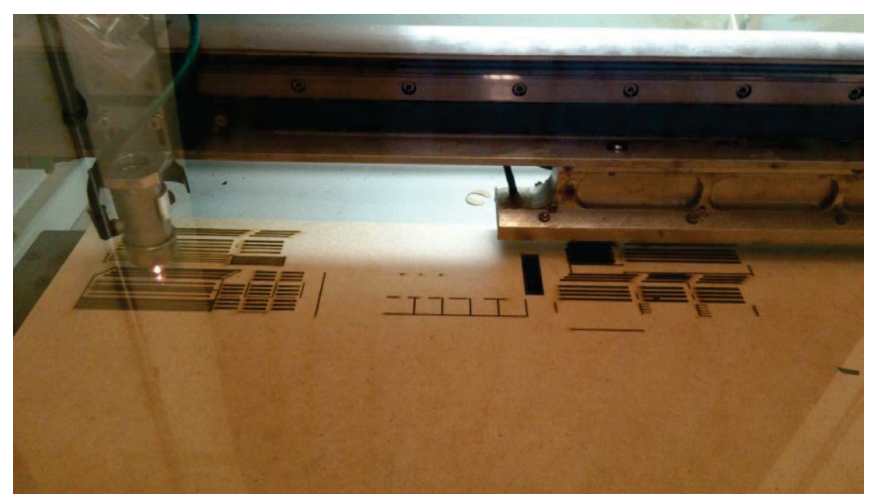

Figura 1: Corte a laser do protótipo na escala 1:25, em MDF 3 mm.

iii) Etapa de Julgamento das Propostas: A comissão julgadora, composta por professores arquitetos e urbanistas, avaliou os projetos conforme os critérios definidos pelo regulamento da maratona, sendo este divididos em aspectos formais: conceito da proposta - relevância, clareza e objetividade; impacto e expressão formal, relação entre conceito e composição formal e funcional final; relação com a temática; e aspectos funcionais: sustentabilidade, acessibilidade, drenagem, exequibilidade, transporte. Todas as equipes deveriam entregar quatro pranchas contendo conceito, memorial descritivo, projeto com plantas, vistas, detalhamentos e perspectivas, e protótipo na escala 1:25.

iv) Etapa de Execução da Proposta: Etapa constituída pelo detalhamento do projeto vencedor, com os devidos ajustes mediante a percepção de possíveis problemas identificados com o modelo reduzido e execução em tamanho real pela equipe. Foram desenvolvidos detalhamentos e ajustes no projeto, e após deu-se início à fase de cortes (Figura 2). Essa fase 
teve acompanhamento de dois docentes e um laboratorista, sendo que a responsabilidade de andamento das atividades ficou a cargo de um acadêmico eleito como regente da equipe. O material utilizado para o modelo em escala 1:1 constituiuse por MDF $18 \mathrm{~mm}$ e os cortes foram executados em uma Computer Numerical Control (CNC). Com a utilização desta fresadora, as peças ainda precisam passar por acabamento para tirar os excessos e retificar as peças.

Após os cortes, o parklet foi montado na Instituição com o apoio de marceneiros para os encaixes e para parafusar as peças, identificando possíveis falhas a tempo de não atrapalhar a montagem efetiva no local determinado para tal (Figura 3). A montagem in loco foi executada no local de uso final no dia 10 de agosto de 2015 e desmontada no dia 31 do mesmo mês, ficando 20 dias à disposição da população.

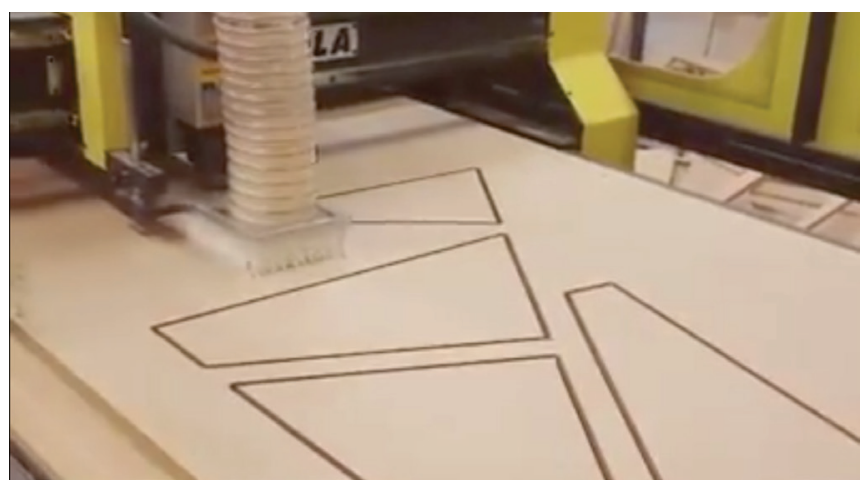

Figura 2: Corte na CNC, na escala 1:1, em MDF $18 \mathrm{~mm}$.

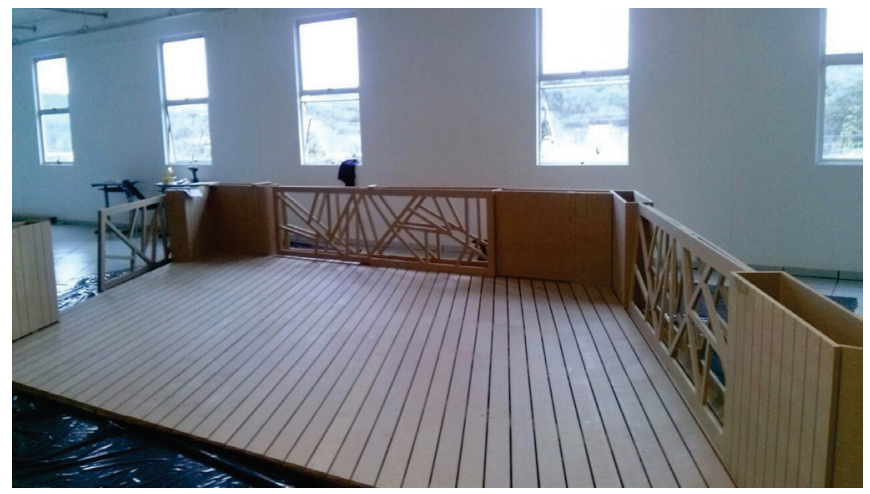

Figura 3: Pré-montagem na instituição para detecção de possíveis falhas.

Após a pré-montagem os acadêmicos decidiram colorir partes do parklet que até então seria todo na cor do MDF cru, instituído pelo regulamento. Como foi possível fazê-lo dentro do tempo estimado para montagem, pois correu tudo como previsto nos cortes e montagem das peças permitiu-se então que fizessem a execução da pintura (Figura 4). Isto só foi possível devido a utilização de maquinários para cortes das peças, e uma rápida pré-montagem antes da execução final do objeto. Neste momento também foi possível verificar a necessidade das cores e definir onde seriam utilizadas.

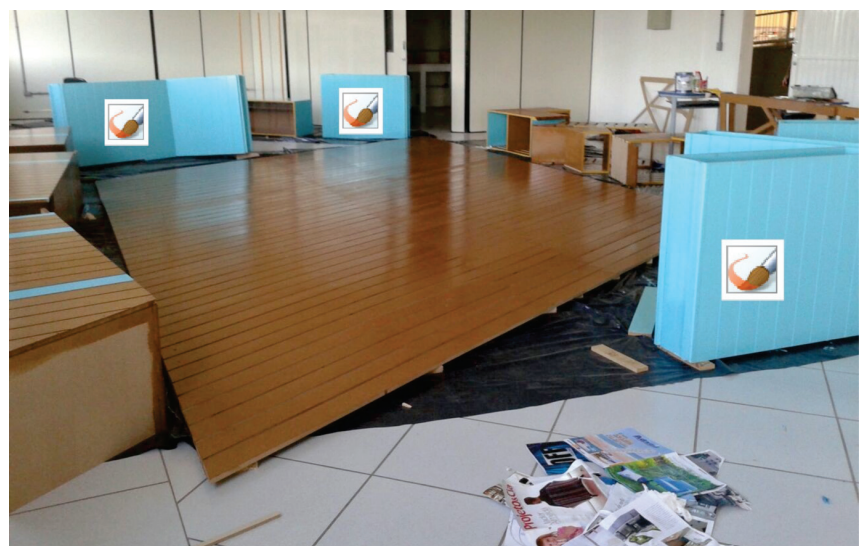

Figura 4: Parklet desmontado para pintura das peças - as peças pintadas são as demarcadas com o pincel.

\section{Resultados}

No total, foram 270 acadêmicos envolvidos na maratona de projetos, distribuídos em 12 equipes. Todas concluíram a atividade e fizeram a entrega do modelo na escala 1:25. Percebeu-se que as equipes que destinaram maior tempo para averiguação do modelo digital assim como do modelo físico, puderam fazer modificações na proposta a fim de ajustes de projeto, comprovando a importância do modelo físico e da prototipagem rápida no processo. Pupo (2009) destaca que a construção da maquete pode revelar erros e desafios no desenvolvimento do projeto e, como foi comprovado na experiência relatada, alguns destes erros não foram percebidos nas representações digitais, mesmo que tridimensionais.

A equipe vencedora apresentou o protótipo que se vê na Figura 5 e, embora tenha sido a proposta que melhor atendeu os requisitos de projeto e os requisitos avaliados na maratona, apresentando, portanto, menor número de falhas, também precisou passar por criteriosa revisão após a entrega, e alguns ajustes ainda se fizeram necessários antes da execução em tamanho real. As principais deficiências encontradas referiram-se a questões de cunho estrutural e de aproveitamento de material e tempo de corte/usinagem, reduzindo, portanto, os custos do produto final.

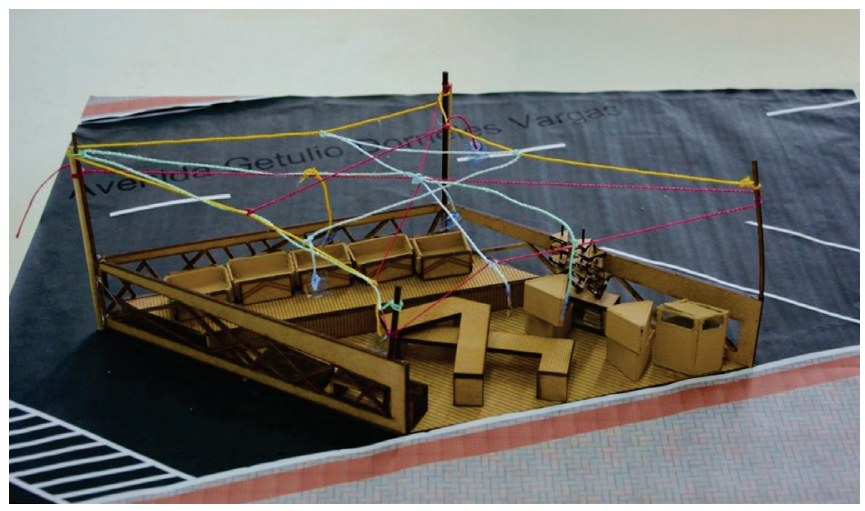

Figura 5: Protótipo da equipe vencedora. 
Isso mostra que apesar de os acadêmicos terem gerado os protótipos na escala 1:25, não estavam sendo cautelosos em consideração à quantidade de chapas disponíveis para a versão final do objeto, reestruturando a lógica do processo da fabricação quando este requisito foi realmente contabilizado.

Assim como afirma Mietti (2012), a prototipagem rápida supre uma deficiência na produção de objetos com nível de detalhamento maior e ganha destaque devido à redução do tempo despendido no desenvolvimento do produto final. No caso da maratona de projetos em questão, os acadêmicos descobririam muitos dos conflitos já sanados na proposta apenas no momento da execução, caso não fosse possível a inserção da prototipagem rápida no processo de projeto. Além disso, a execução do modelo em tamanho real só seria possível com o auxílio de processos de marcenaria convencional, o que tiraria a autonomia dos autores no detalhamento e soluções das possíveis falhas. Percebeu-se, portanto, a melhor comunicação entre os agentes envolvidos, através da ampla visão real do resultado final.

Na Figura 6 é possível perceber o parklet em tamanho real e, se comparada à Figura 5, observa-se as alterações do projeto, como redução da quantidade de mobiliário a fim de facilitar a execução e melhorar o aproveitamento de material; a duplicação dos painéis laterais e a criação de caixões de mdf para dar suporte estrutural aos painéis delimitadores do parklet.

Atualmenteo parklet está montado no pátio da Instituição

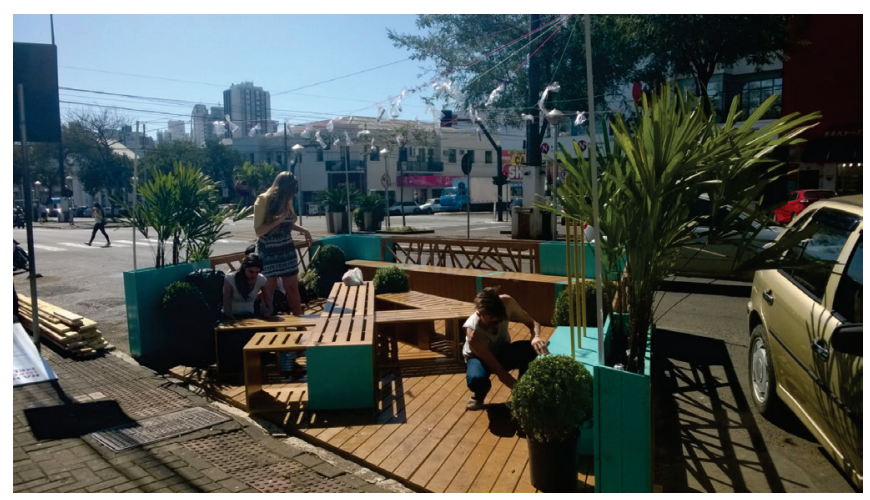

Figura 6: Parklet montado na Av. Getúlio Vargas.

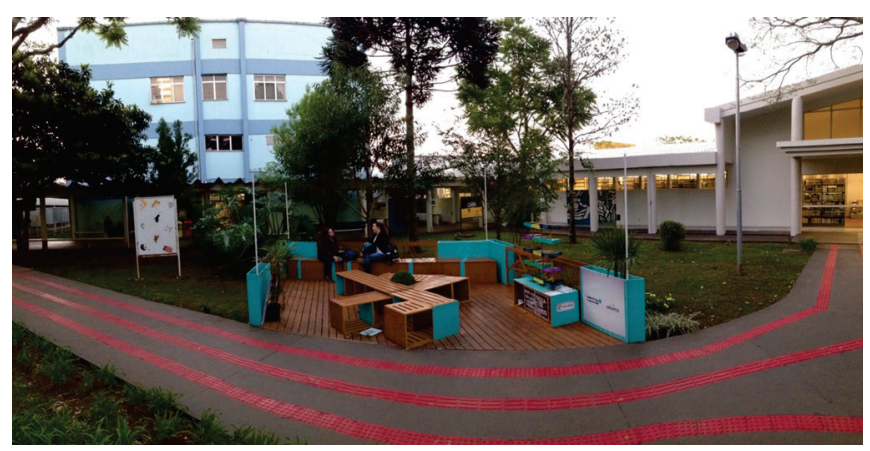

Figura 7 - Parklet montado na Instituição.
(Figura 7), e esta facilidade de montagem e desmontagem se dá pelo fato da facilidade de encaixes e montagens de peças estruturadas em projetos tridimensionais pensados por meio da fabricação digital.

\section{Discussão}

Este estudo contribui para a discussão sobre técnicas e funções que o uso das tecnologias de prototipagem rápida e fabricação digital podem proporcionar ao processo de projeto emarquitetura eurbanismo. Os resultadosapontam a melhoria do processo de projeto aplicado ao ensino de arquitetura e urbanismo principalmente no que se refere à identificação de falhas e conflitos das propostas, o que comumente acaba passando despercebido por estudantes, nas diversas fases do curso. Isso comprova a possibilidade de uma percepção mais clara e ampla de todos os envolvidos no processo, como afirma Pupo (2009). Orciuoli (2009) também relata que as novas tecnologias contribuem com tarefas relacionadas ao projeto, sobretudo pelo fato de gerar informação digital, com suas particularidades quanto ao gerenciamento, intercâmbio entre colaboradores, capacidades de experimentação.

Assim como identificado por Bruscato et al. (2014) percebeu-se a prototipagem como ferramenta de avaliação de viabilidade e melhoria da estrutura formal do projeto, proporcionando melhor atendimento dos requisitos de projeto, o que constitui a fabricação digital e a prototipagem rápida como ferramentas importantes na concepção e desenvolvimento projetual. Além disso, o uso de fabricação digital com cortadora a laser e CNC torna possível a construção de protótipos de forma rápida, interferindo desde o processo criativo até a visualização e realização de testes de viabilidade estrutural, de ergonomia, de inserção no local e redução de custos com melhor aproveitamento de material. Em questionário aplicado aos participantes da $3^{a}$ Maratona de Projetos - Ateliê Vertical, onde 101 participantes responderam, 74,2\% afirmaram que sua equipe conseguiu verificar erros e acertos após a execução do protótipo e 85\% afirmou que mudaria e evoluiria seu projeto após a mesma caso houvesse mais tempo para rediscutir o projeto e realimentar os detalhamentos assim como reformular decisões estruturais e até conceituais.

Ainda quando questionados sobre a fase em que o protótipo deve ser executado, 45,5\% afirma que deve ser executado como parte do processo de projeto e como produto final, 42,6\% afirma que deve ser executado apenas como parte do processo de projeto e apenas $11,9 \%$ afirma que ele deve fazer parte apenas do produto final do projeto arquitetônico. Mesmo que 11,9\% mostre ser menor número, e considerando que parte dos acadêmicos que participam da Maratona são iniciantes, de primeiro e segundos períodos, ainda assim o número mostra que é importante adotar o uso de protótipos nos processos de projetos curriculares, para que os acadêmicos percebam a necessidade de testar e verificar de forma prática os possíveis erros que podem acontecer na vida profissional. 
Segundo Florio e Tagliari (2011), embora os protótipos normalmente tenham uma função puramente representativa, são altamente atraentes para experimentar alterações no projeto durante sua concepção. Isso ocorre porque as mudanças nos protótipos virtuais podem ser rapidamente transmitidas para novos protótipos rápidos, especialmente com o objetivo de avaliar e comparar propostas. Em arquitetura, além de servir para testar, os protótipos rápidos exercem a função de fazer o projetista compreender, sintetizar e avaliar a proposta arquitetônica, em seus múltiplos aspectos como para comunicar facilmente as intenções projetuais dos arquitetos. No caso da experiência aqui relatada, a percepção no protótipo foi de fundamental importância para a execução em tamanho real e ainda gerou questionamentos projetuais em toda a equipe.

Com a montagem do produto em tamanho real foi possível verificar que a inclusão de tecnologias digitais na arquitetura, utilizando a mesma informação tanto para a representação quanto para a construção, faz com que estas tecnologias auxiliem novas práticas de projeto, melhorando questões de tempo de execução, liberdade geométrica, qualidade no produto final e controle da obra assim como afirma Orciuoli (2009) e que relata que um novo meio em que se pode construir um objeto é com esta inclusão de tecnologias digitais. No caso da execução do parklet o tempo total de carregamento e descarregamento do material, transporte e montagem do mesmo foi de 3,5 horas, sendo que o tempo efetivo de montagem foi de 1,5 horas, comprovando melhoria na eficiência do processo de execução como um todo.

Corroborando com os resultados encontrados por Oliveira e Fabrício (2009), acredita-se que a inserção de disciplinas que incentivem o uso das novas tecnologias para melhoria do processo de desenvolvimento do projeto é fundamental para a formação do aluno. Como afirmam os autores, neste cenário, a automação da produção das maquetes é essencial para que o modelo virtual, complexo, seja diretamente enviado para impressão, possibilitando a conformação do modelo final.

Ainda Florio e Tagliari (2011) afirmam que protótipos rápidosampliam a percepçãodeespaçopor meiodotoquefísico. Afirmam ainda que se torna mais fácil distinguir diferentes conformações geométricas complexas tateando e girando os protótipos diante dos olhos. Assim, por mais precisa que seja a imagem e a capacidade de processar e mostrar imagens em tempo real, com definições convincentes de sombras e cores, os modelos feitos no ambiente virtual estão distantes daquilo que pode considerar natural. Desse modo, acredita-se que a experiência aqui relatada contribui para a visualização desta necessidade, comprovando que tais mudanças no ensino podem resultar em significativas melhorias da aprendizagem do acadêmico e, consequentemente, em um profissional melhor preparado para os desafios do mercado.

Ter a possibilidade de fabricar dentro da Universidade um objeto em tamanho real, neste caso tratando-se de equipamento urbano público, a partir de um projeto acadêmico enriquece não somente as discussões metodológicas de projetos arquitetônicos, mas possibilita transformar projetos em realidade; devidamente orientados por profissionais; facilitando a compreensão do processo de projetação e execução no acadêmico, tornando-o mais reflexivo e responsável pelas suas ações projetuais.

Percebeu-se que a inclusão dos acadêmicos na execução do objeto em estudo estimulou o comportamento de proatividade e responsabilidade sobre o processo, o que contribui de modo significativo na formação de estudantes autônomos e futuros profissionais reflexivos. Salienta-se que, se o processo tivesse ocorrido de forma tradicional, com ferramentas tradicionais de marcenaria, o envolvimento dos acadêmicos não teria sido tão intenso e a contribuição da atividade enquanto estratégia pedagógica não teria sido tão significativa, o que reforça a importância da inserção das novas tecnologias no processo de ensino-aprendizagem.

\section{Agradecimentos}

Á equipe do PRONTO 3D - Chapecó, pela disponibilidade e dedicação no atendimento aos acadêmicos.

À Unochapecó, que forneceu suporte financeiro e de recursos humanos para viabilizar a execução do parklet no centro da cidade.

\section{Referências}

Bruscato, M. U.; Brendler, C. F.; Viaro, F. S.; Teixeira, F. G.; Silva, R. P. (2014). Uso da fabricação digital e prototipagem no desenvolvimento do projeto de produto: análises de simulações digitais. Blucher Design Proceedings, V. 1, n. 7. 2318-6968. DOI: 10.5151

Florio, W. \& Tagliari, A. (2011). Fabricação digital de maquetes físicas: tangibilidade no processo de projeto em Arquitetura. Exacta, 9(1) 125-136. Recovered from http:// www.redalyc.org/articulo.oa?id=81018619010

Mietti, M. A.; Lima, J. L. A. (2012). O uso do sistema JPS 5 no ensino da prototipagem rápida. Retirado do site da Associação Brasileira de Engenharia de Produção: http://www.abepro. org.br/biblioteca/ENEGEP1999_A0342.PDF

Miysaka, E. L.; Fabricio, M. M. (2015, Jun 08 - 10). Digital Fabrication in Brazil: Academic Production in the last decade. International Conference CAAD Futures, 16th. Retirado de: http://www.researchgate.net/publication/279749703_ Digital_Fabrication_in_Brazil_Academic_Production_in_ the_last_decade

Pupo, R. T. (2009). Inserção da PROTOTIPAGEM e FABRICAÇÃO DIGITAIS no processo de projeto: um novo desafio para o ensino de arquitetura. Tese disponível em: http://home.fa.utl.pt/ progfabarq/tese.pdf. PRONTO 3D inovando em Santa Catarina: o primeiro FabLab do Estado. Retirado de: http// venhainovarcomfloripa.com/blog/?p=422.

Oliveira, M. R.; Fabricio, M. M.: (2009). Modelos físicos e virtuais como ferramentas do ensino de projeto de arquitetura: relato de uma vivência. In: Congresso Iberoamericano de 
Gráfica Digital SIGRADI. Retirado de: http://cumincades.scix. net/data/works/att/sigradi2009_816.content.pdf (2009) Prototipagem rápida como ferramenta de projeto e ensino de arquitetura: visita a laboratórios de prototipagem. In: IV Projetar, São Paulo.

Orciuoli, A. (2010) SIGRADI São Paulo 2009: Quebrando tabus.
Revista Drops. 2175-6716. Retirado de: http://www.vitruvius. com.br/revistas/read/drops/10.030/2115.

(2009) Representar, Projetar e Construir. Novos paradigmas a partir do desenho por computador. In: Congresso Iberoamericano de Gráfica Digital SIGRADI, São Paulo. 